\title{
THE EFFECT OF MEDICATION REMINDER CHART ON LEVEL OF ADHERENCE IN DIABETES MELLITUS TYPE 2 PATIENTS AT RSUD SLEMAN YOGYAKARTA
}

\author{
Yunita Suffiana, Fita Rahmawati*, Tri Murti Andayani
}

\begin{abstract}
Laboratory Pharmacology and Clinical Pharmacy, Faculty of Pharmacy, Universitas Gadjah Mada. Skip Utara 55281 Yogyakarta
\end{abstract}

Submitted: $12-08-2016$

Revised: 25-09-2016

Accepted: $10-01-2017$

*Corresponding author

Fita Rahmawati

Email:

malihahanun@yahoo.com

\begin{abstract}
Patient adherence is a key factor that determines the outcome of diabetes mellitus therapy. This study was conducted to determine the effect of a medication reminder chart on level adherence and clinical outcome in patients with Type 2 diabetes mellitus. The experimental study used pretest-posttest design with control group was conducted during February until April of 2016 at Sleman Hospital in Yogyakarta. Patients were categorized into two groups of different subjects, who received of medication reminder chart tools were 40 patients (Code A) and the other 40 patients were assigned to control group (Code B). Morisky Medication Adherence Scale of 8-item (MMAS-8) was used to measure adherence. Clinical outcome were measured based on FBG decrease $(\mathrm{mg} / \mathrm{dl})$. Two independent sample t-test was using to determine the mean differences of the average score of the adherence level before and after using the medication reminder chart. The results of this study showed that Medication Reminder Chart compared control groups improved adherence $(p=0.000)$ but did not improve clinical outcome $(p=0.411)$. The pharmacist might use The Medication Reminder Chart to improve medication adherence for chronic disease.
\end{abstract}

Key words: Compliance, Clinical outcome, MMAS-8, Medication Reminder Chart

\section{INTRODUCTION}

Diabetes mellitus was in the list of top 10 highest prevalence disease in Sleman (Dinkes Sleman, 2013). The type 2 of diabetes mellitus is one of metabolic disease with increasing prevalence over years, which one cause lower limb amputations, blindness, and kidney failure in 20-74 years old (CDC, 2009). The type 2 diabetes mellitus was chronic metabolic disease with multiple etiology characterized by hyperglycemia and impaired metabolism of carbohydrates, lipids and proteins as a result of insufficiency of insulin function. Insufficiency of insulin function is known to be caused by impaired or deficient production of insulin with beta cells Langerhans of the pancreas gland, or due to reduced the responsiveness of cells on insulin (Wells et al., 2009).

Patients who are non adherence to treatment could make serious problem and are great challenge in making a treatment succeed. The success of treatment is not only adherence, but included also monitoring of blood glucose, dietary changes, care of foot hygene, and exercise (Santosa, 2011). Inadherence is suspected to be caused by factors related to the patient such as age, gender, education or related therapy patient as long diagnostics, complexity of treatment and side effects of drugs (Divya and Nadig, 2015). Based on the WHO report of 2003, the average long-term treatment of adherence in chronic diseases in developed countries reached $50 \%$, while in developing countries is lower (Cramer, 2004). The study in Sudan, showed that medications adherence was $100(44.2 \%)$ for patients on oral medications and $57(45.6 \%)$ for insulin users (El-Hadiyah $e t$ al., 2016). The success of treatment in type 2 diabetes mellitus was influenced by patient adherence in taking medicine (BPOM, 2006)

One of the instruments used to assess the adherence patients with type 2 diabetes mellitus is the Morisky Medication Adherence Scale (MMAS-8) with eight item questionnaire developed by Morisky et al., (2008). This 
questionnaire has been evaluated with high reliability (0.83), high sensitivity and specificity (Morisky et al., 2008). Another method for assessing adherence was pill count. Pill count was known to have high accuracy (Lam and Paula, 2015).

In this study, Medication Reminder Chart tools used to improve patient adherence with medication use. This method was chosen because it offers cheap, easy method that had proven its capability to improve adherence with medication use (Conn et al., 2009).

\section{MATERIAL AND METHODS Subjects research}

Subjects were outpatients with type 2 diabetes mellitus with complication such are hypertension, dislipidemia, neuropathy diabetic, and chronic heart failure. The study begin in February until March of 2016 at Sleman Hospital in Yogyakarta. The total number of patients is 80 . The number of subjects was obtained from sample size calculation in experimental studies, where the outcome varians $\left(\sigma^{2}\right)$ is $47,8^{2}$ and $\mu_{1}-\mu_{2}$ are $158,0-126,9$ that were obtained from research conducted by Wishah et al., (2015) and the results obtained from sample size calculation in this study is 29 patients, typically added $20 \%$ to avoid drop out $(29+6=35$ patients), so in this study required minimal of 35 subjects of each groups. The subjects were divided into two groups. The first group was given the intervention of Medication Reminder Chart which consisted of 40 patients and control group consisted of 40 patients. Inclusion criteria were patients who was diagnosed with type 2 diabetes mellitus or with complication, subjects $\geq 26$ years old, fasting blood glucose $\geq 100 \mathrm{mg} / \mathrm{dl}$, patients adherence with scale of MMAS less than 8, patients who never used Medication Reminder Chart before, willing to participate in the study by signing an informed consent. Exclusion criteria were pregnant patients.

The Medication Reminder Chart is a tool or medical records used by patients after taking medication. The part of medication reminder consists of drugs name, indication, and the strength of doses were designed by researchers with reference to the meta-analysis which is conducted by Conn et al., (2009). Medication reminder chart is benefecial for patients who have gotten complex treatment, as well as useful for patients who use one or two of drug with specific problems when the patients has activity outside or difficulty to remember taking medication at a certain time (Raynor, 2011).

\section{Research data}

Data obtained from medical records included age, gender, education and employment history, body mass index, long term diagnose, smoking history, comorbid, diet of carbohydrate, type of treatment, physical exercise, fasting blood glucose level and interviewed with patients included using of Morisky Medication Adherence Scale Questionnaire with eight items questionnaire and pill count. Data were obtained prospectively and sampling methods using random allocation sampling determined with random numbers (0-99) with 6 bloks sequences patterns A and B, A code assiegned for Medication Reminder Chart and B for Control groups, randomization was done using Microsoft Excel.

Adherence of patients was evaluated by MMAS-8 questionnaire cales that categorize patients into three categories of adherence. The first one was high adherence patients with a score of 8 on the scale, medium adherence with a score of 6-7, and low adherence with a score < 6 (Morisky et al., 2008). Therapy outcome of fasting blood glucose level measuring before and after intervention. Expected therapy goal of fasting blood glucose is $<110 \mathrm{mg} / \mathrm{dL}$.

\section{Analysis of research finding}

Patients was classified by age, gender, education and employment history, type of treatment, body mass index, long term diagnose, smoking history, comorbid, diet of carbohydrate, physical exercise were analyzed with Chi-Square statistic to investigate whether distributions of categorical variables differ from one another. The adherence with MMAS-8 questionnaire and clinical outcome were determined before and after treatment. Kolmogorov smirnov test is used to evaluate the variable data is sufficiently normal. The adherence scale (MMAS-8) questionnaire and clinical outcome (FBG) $(\mathrm{mg} / \mathrm{dl})$. 
Yunita Suffiana

Table I. Characteristics data of medication reminder chart and control groups

\begin{tabular}{|c|c|c|c|c|c|}
\hline \multicolumn{2}{|c|}{ Characteristics } & $\begin{array}{c}\text { Medication Reminder } \\
\text { Chart n }(\%)\end{array}$ & $\begin{array}{c}\text { Control } \\
\text { n }(\%)\end{array}$ & $\begin{array}{c}\text { Total Subject } \\
\text { n }(\%)\end{array}$ & $\begin{array}{c}p \\
\text { value }\end{array}$ \\
\hline \multirow{2}{*}{ Gender } & Male & $13(32.5)$ & $14(35)$ & $27(33.75)$ & \multirow{2}{*}{$0.813^{\mathrm{a}}$} \\
\hline & Female & $27(67.5)$ & $26(65)$ & $53(66.25)$ & \\
\hline \multirow{2}{*}{ Age } & Adult & $28(70)$ & $19(47.5)$ & $47(58.75)$ & \multirow{3}{*}{$0.041^{\mathrm{a}}$} \\
\hline & Elderly & $12(30)$ & $21(52.5)$ & $33(41.25)$ & \\
\hline & Underweight & $2(5)$ & $1(2.5)$ & $3(3.75)$ & \\
\hline \multirow[t]{3}{*}{ Body weight } & Normal weight & $18(45)$ & $19(47.5)$ & $37(46.25)$ & \multirow[t]{3}{*}{0.747} \\
\hline & Overweight & $20(50)$ & $20(50)$ & $40(50)$ & \\
\hline & Uneducated & $1(2,5)$ & $1(2.5)$ & $2(2.5)$ & \\
\hline \multirow[t]{2}{*}{ Education } & Elementary & $13(32,5)$ & $16(40)$ & $29(36.25)$ & \multirow[t]{2}{*}{$0.508^{a}$} \\
\hline & High School & $26(65)$ & $23(57.5)$ & $49(61.25)$ & \\
\hline
\end{tabular}

Table II. Characteristics data of medication reminder chart and control groups

\begin{tabular}{|c|c|c|c|c|c|}
\hline \multicolumn{2}{|c|}{ Characteristics } & $\begin{array}{c}\text { Medication Reminder } \\
\text { Chart n }(\%)\end{array}$ & $\begin{array}{l}\text { Control } \\
\text { n }(\%)\end{array}$ & $\begin{array}{c}\text { Total Subject } \\
\text { n }(\%)\end{array}$ & $\begin{array}{c}p \\
\text { value }\end{array}$ \\
\hline \multirow{2}{*}{ Occupation } & Occupied & $18(45)$ & $14(35)$ & $32(40)$ & \multirow{2}{*}{$0.361^{\mathrm{a}}$} \\
\hline & Not occupied & $22(55)$ & $26(65)$ & $48(60)$ & \\
\hline Carbohydrate & Controlled & $23(57.5)$ & $25(62.5)$ & $48(60)$ & \multirow{2}{*}{$0.648^{a}$} \\
\hline Diet & Uncontrolled & $17(42.5)$ & $15(37.5)$ & $32(40)$ & \\
\hline \multirow{2}{*}{ Physical exercise } & Regular & $3(7.5)$ & $1(2.5)$ & $4(5)$ & \multirow{2}{*}{$0.308^{a}$} \\
\hline & Not regular & $37(92.5)$ & $39(97.5)$ & $76(95)$ & \\
\hline \multirow{2}{*}{ Smoking } & Yes & $4(10)$ & $7(17.5)$ & $11(13.75)$ & \multirow{2}{*}{$0.330^{\mathrm{a}}$} \\
\hline & No & $36(90)$ & $33(82.5)$ & $69(86.25)$ & \\
\hline Diagnosed for & $<1$ year & $3(7.5)$ & $7(17.5)$ & $10(12.5)$ & \multirow{4}{*}{$0.369^{\mathrm{a}}$} \\
\hline \multirow{3}{*}{ DM } & $1-5$ years & $11(27.5)$ & $11(27.5)$ & $22(27.5)$ & \\
\hline & $<5$ years & $26(65)$ & $22(55)$ & $48(60)$ & \\
\hline & $\mathrm{DM}$ & $10(25)$ & $7(17.5)$ & $17(21.25)$ & \\
\hline \multirow[t]{2}{*}{ Comorbid } & $\mathrm{DM}+\mathrm{HT}$ & $21(52.5)$ & $16(40)$ & $37(46.25)$ & \multirow[t]{2}{*}{$0.160^{\mathrm{a}}$} \\
\hline & $\mathrm{DM}+$ others & $9(22.5)$ & $17(42.5)$ & $26(32.5)$ & \\
\hline \multirow{2}{*}{$\begin{array}{l}\text { Prescription of } \\
\text { antidiabetic }\end{array}$} & Single & $15(37.5)$ & $15(37.5)$ & $30(37.5)$ & \multirow{2}{*}{$1.0^{\mathrm{a}}$} \\
\hline & Combined & $25(62.5)$ & $25(62.5)$ & $50(62.5)$ & \\
\hline
\end{tabular}

Data pairs which were not normally distributed were analyzed with Two Independent samples t-test (Wilcoxon), while paired data which were normally distributed were analyzed with Two Independent samples t-test (Mann-Whitney).

\section{RESULTS AND DISCUSSIONS Patient characterstics}

Characteristics of subjects in this study was analyzed to determine the proportions between the treatment group and control in baseline conditions (Table I).

The results from whole characteristics data analysis upon the two study groups insignificant value of $\mathrm{p}>0.05$, with similar proportion between the two groups. Characteristic data of the subjects age showed significant value of $\mathrm{p}<0.05$, which showed different proportion between two groups.

\section{Identification of adherence with pill count after treatment}

Table II showed that pill count analysis result was categorized into two groups. The first group for adherent patients with score of $80-100 \%$ and non-adherent patients with score under $80 \%$. 
Table III. Profile of patient adherence with pill count

\begin{tabular}{lcccc}
\hline \multirow{2}{*}{ Patients adherence profile } & \multicolumn{2}{c}{ Medication Reminder Chart } & \multicolumn{2}{c}{ Control } \\
\cline { 2 - 5 } & $\mathbf{N}$ & $\mathbf{\%}$ & $\mathbf{N}$ & $\mathbf{\%}$ \\
\hline Adherent & 21 & 52.5 & 15 & 37.5 \\
Non adherent & 19 & 47.5 & 25 & 62.5 \\
\hline
\end{tabular}

Table IV. The median difference of adherence effect measured with MMAS-8 score of medication reminder chart and control groups.

\begin{tabular}{lccc}
\hline Grouping & Median (Maximum-Minimum) & $\boldsymbol{p}$ value & Median different \\
\hline Medication Reminder Chart & $1.50(3-0)$ & $0.000^{\mathrm{a}}$ & 0.5 \\
Control & $1.00(3-0)$ & & \\
\hline
\end{tabular}

Profile of patient adherence by pill count of Medication Reminder Chart group was higher with percentage of $52.5 \%$, compared to control groups with percentage of $47.5 \%$ (Table III).

\section{The effect of medication reminder chart to patient adherence}

Blood glucose control was significantly associated with adherence to treatment thus reducing the complications of diabetes, hospitalizations, costs, and mortality. Medication Reminder Chart was effective in improving patient adherence with risk of therapy regiments complexity (Manmohan et al., 2012). The Median difference of adherence measured with MMAS-8 score of Medication Reminder Chart and control group, in this study using a non-parametric analysis with Two Independent Samples test (Mann-Whitney) for data unpaired groups (Table IV).

A significant effect of Medication Reminder Chart to increase adherence of MMAS-8 score from pre-test to post-test higher than control group with $\mathrm{p}$ value $\mathrm{p}=0.000$ and median different of 0.5 . This study same as the research conducted by Conn et al which shown that intervention of Medication Reminder Chart could improve adherence, especially in elderly patients in treatment (Conn et al., 2009) (Table IV) .

\section{The effect of medication reminder chart on clinical outcome}

One of the key factors to achieve therapeutic goals is patient adherence. Low adherence could affect bad clinical outcome. Optimal adherence of tretament would succesesfully improve therapeutic efficacy in the treatment of all chronic diseases and improved quality of life patients (Santosa, 2011). The Median different of clinical outcome in Medication Reminder Chart and control group (Table IV).

The result form table IV showed insignificant effect of Medication Reminder Chart compared to control groups in the decrease of fasting blood glucose level in type 2 diabetes mellitus patients with $\mathrm{p}$ value $\mathrm{p}=0.411$ and median difference of 5.5. Basically the improvement of clinical outcomes affected by increased adherence, which in this study was measured based on interviews with questionnaires MMAS-8. The results showed patients adherence was increased after giving medication reminder chart, but even with increased adherence, the number of forgetting patients greater in adult category which was caused by being busy on working that sometimes lead them to be forgotten to take medication. Other than that, based on the results of interviews, some patients forgot to fill medication Reminder Chart after taking medication because of being busy, while others were not filling the medication Reminder Chart because they assumed that they know the schedule for taking the medication (thinks that filling the chart was not important), and others consider medication Reminder Chart is needed to help them remember the schedule for taking the medication and could be disciplined in 
Table V. Median different of FBG in Medication Reminder Chart and control Group

\begin{tabular}{|c|c|c|c|}
\hline Groups & $\begin{array}{c}\text { Median (Maximum-Minimum) } \\
(\mathrm{mg} / \mathrm{dL})\end{array}$ & $p$ value & Median different \\
\hline $\begin{array}{l}\text { Medication Reminder Chart } \\
\text { Control }\end{array}$ & $\begin{array}{c}16(200-(-73) \\
10.50(295-(-132)\end{array}$ & $0.411^{a}$ & 5.5 \\
\hline
\end{tabular}

Table VI. Spearman Correlation Analysis between adherence and clinical outcomes of patients with Type 2 diabetes mellitus

\begin{tabular}{ccc}
\hline Variable & $\boldsymbol{p}$ value & $\mathbf{R}$ \\
\hline MMAS- FBG $(\mathrm{mg} / \mathrm{dL})$ & 0.029 & 0.213 \\
\hline
\end{tabular}

taking medicine. Therefore it is considered important to inform patients to use medication Reminder Chart to improve adherence. The results of the analysis showed the correlation between adherence and clinical outcomes in patients with Type 2 diabetes (Table V).

Correlation between adherence and FBG levels with a significance $\mathrm{p}=0.029$, and positive correlation coefficient of $(\mathrm{r}=0.213)$, it means that higher adherence would increase the clinical outcome, the strength of the correlation is weak $(\mathrm{r}=0.2-<0.4)$, which indicated while the correlation was positive, but compared to the clinical outocme between the two groups, it could not significantly decrease fasting blood glucose level after Medication Reminder Chart (Table VI).

The success of treatment was not completely influenced by adherence of drug use. The success of therapy in type 2 diabetes mellitus could be improved by controlling the diet, monitor blood glucose levels and exercise (Santosa, 2011).

\section{CONCLUSION}

Medication Reminder Chart could improve adherence of patients compared to control group in Type 2 diabetes mellitus patients $(\mathrm{p}=0.000)$ with median difference of 0.5. Medication Reminder Chart could not improve clinical outcomes in treatment group compared to control groups in patients with Type 2 diabetes mellitus $(\mathrm{p}=0.411)$ with median difference of 5.5. Increased compliance could increased clinical outcome $(p=0.029)$, with a positive correlation and the strength of weak correlation $(r=0.213)$.

\section{LIMITED STUDY AND SUGGESTION}

Many factors can not be controlled in type 2 diabetes mellitus outpatient such as diet, excercise etc. Required modifications Medication Reminder Chart more informative (name of medication, dosage, frequency of use, indications, schedule for taking medication) and the instructions for filling the sheet of Medication Reminder Chart.

\section{REFERENCES}

BPOM, 2006. Kepatuban Pasien: Faktor Penting Dalam Keberbasilan Terapi. Badan POM Republik Indonesia, Jakarta.

Cramer JA., 2004. A Systematic Review of Adherence With Medications for Diabetes. Diabetes Care, 27: 1218-1224.

CDC, 2009. The Power of Prevention Chronic disease the public health challenge of the 21st century.

Divya, S. dan Nadig, P., 2015. Factors Contributing To Non-Adherence To Medication among Type 2 Diabetes Mellitus In Patients Attending Tertiary Care Hospital In South India. Asian J. Pharm. Clin. Res., 8: 2

El-Hadiyah TM., Abdelhaleem MM., Hisham MA., Abubakr K., 2016. Factors Affecting Medication Non Adherence in Type 2 Sudanese Diabetic Patients: Pharmacology \& Pharmacy, 7,141-146.

Lam WY., Paula F., Medication Adherence Measures: An Overview, BioMed Research 
International Volume 2015, Article ID 217047, $\quad 12 \quad$ pages http://dx.doi.org/10.1155/2015/217047 Morisky DE., Ang A., Krousel-Wood M., Ward HJ., 2008. Predictive Validity of A Medication Adherence Measure in an Outpatient Setting. J. Clinical bypertension (Greenwich, Conn.), 10: 348-354

Conn VS., Hafdahl AR., Cooper PS., Ruppar TM., Mehr DR., Russell CL., 2009. Interventions to improve medication adherence among older adults: metaanalysis of adherence outcomes among randomized controlled trials. The Gerontologist, 49: 447-462.

Dinas Kesehatan Kabupaten Sleman, 2013, Profil Kesehatan Sleman 2013 Sub Bagian Perencanaan dan Evaluasi, Sleman.

Raynor T. 2011. Medication Reminder Chart- a Key Tool For Delivering The New
Medicine Service. The Pharmaceutical Journal. September 2011.

Santosa M., 2011, Pengenalan Penyakit DM Dan Penanganannya Dewasa ini, http://www.pbpapdi.org/papdi.phppb= detil_berita\&kd_berita=87(diakses tanggal 25 januari 2016)

Wells BG., Dipiro JT., Schwinghammmer TL., Dipiro CV., 2009. Pharmacotherapy Handbook.McGraw-Hill Medical Pub.Division, New York.

Wishah RA., Omar AA., Abla MA. 2015. Impact of Pharmaceutical Care Intervention on Glycemic Control and Other Health-Related Clinical Outcome in Patients with Type 2 Diabetes :RCT, Diabetes and Metabolic Syndrome: Clinical Research \& Reviewes 9 271-276. 